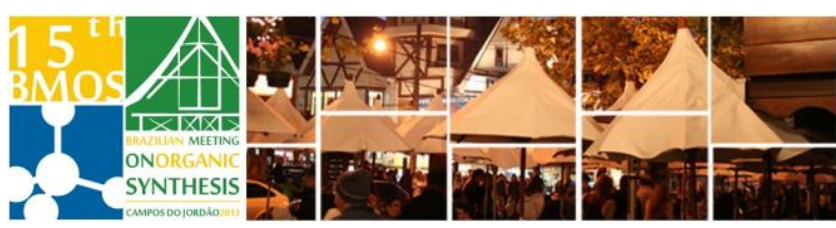

\title{
Evaluation of lipases from metagenomic in kinetic resolution of secondary alcohols
}

\author{
Allen C. S. Costa, Talita C. Fraiz, Robson Alnoch, Aline D. Madalozzo, Alfredo R. M. \\ de Oliveira, Nadia Krieger, Leandro Piovan*
}

Departament of Chemistry, Federal University of Paraná, CEP 81.531-990, CP 19081, Curitiba-PR, Brazil.

*e-mail corresponding author: Ipiovan@quimica.ufpr.br

Keywords: lipases, secondary alcohols, kinetic resolution

\section{INTRODUCTION}

Conventional techniques of enzymes relies on isolation and cultivation of microorganism. Since it is estimated that only $1-10 \%$ of microorganisms are culturable different approaches have been used for obtaining new enzymes of biotechnological interest. Metagenomic technique obviate this need by directly extracting of DNA fragments from environment and subsequent sequencing, analysis and overexpression into a host microorganism culturable in the laboratory ${ }^{1}$. Since lipases obtained by metagenomic have not been evaluated for their applicability in organic synthesis, we decided to evaluate the lipases LipC6G9 and LipC12, wich were obtained from a metagenomic library constructed from a sample of animal fat contaminated soil $^{2}$, in the kinetic resolution of secondary alcohols and respective esters 1a-1d.

Figure 1. Enzymatic kinetic resolution reactions mediated by: LipC6G9 and LipC12. A) Transesterification and B) Hydrolysis.

A)
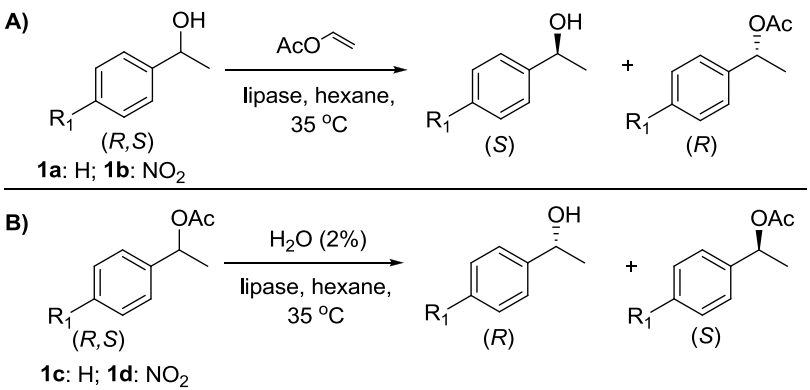

\section{RESULTS AND DISCUSSION}

LipC6G9 and LipC12, were previously characterized and supported in Accurel and Immobead $^{\circledR}$ respectively. The reactions were carried out in sealed vials under magnetic stirring at $35{ }^{\circ} \mathrm{C}$, the results are represented in Table 1.

Table 1. Enzymatic kinetic resolution of secondary alcohols and esters by LipC6G9 and LipC12.

\begin{tabular}{|c|c|c|c|c|c|c|c|}
\hline Entry & Lipase & Compd. & $\begin{array}{c}\text { Time } \\
\text { (h) }\end{array}$ & $\begin{array}{c}C \\
(\%)\end{array}$ & $\begin{array}{l}e e_{s} \\
(\%)\end{array}$ & $\begin{array}{l}e e_{p} \\
(\%)\end{array}$ & $E$ \\
\hline 1 & \multirow{4}{*}{ LipC6G9 } & $1 \mathrm{a}$ & 30 & 49 & 99 & 99 & $>200$ \\
\hline 2 & & $1 b$ & 120 & 26 & 34 & 99 & $>200$ \\
\hline 3 & & $1 c$ & 144 & 18 & 22 & 99 & $>200$ \\
\hline 4 & & 1d & 24 & 47 & 90 & 99 & $>200$ \\
\hline
\end{tabular}

$15^{\text {th }}$ Brazilian Meeting on Organic Synthesis - $15^{\text {th }}$ BMOS - November 10-13, 2013 - Campos do Jordão, Brazil

\begin{tabular}{|c|c|c|c|c|c|c|c|}
\hline 5 & \multirow{4}{*}{ LipC12 } & $1 \mathrm{a}$ & 216 & 14 & 4 & 24 & 2 \\
\hline 6 & & $1 b$ & 216 & 10 & 12 & 99 & $>200$ \\
\hline 7 & & 1c & 72 & 14 & 16 & 99 & $>200$ \\
\hline 8 & & 1d & 120 & 49 & 94 & 99 & $>20$ \\
\hline
\end{tabular}

c. and e.e: (conversion and enantiomeric excess) were determined by GC using chiral column Chiral-Dex-CB. E (enantiomeric ratio) ${ }^{3}$. Reaction Conditions: $0,1 \mathrm{mmol}$ of compounds 1a, $1 \mathrm{~b}$ e $1 \mathrm{c}, 2 \mathrm{~mL}$ Solvent, $100 \mathrm{mg}$ of supported enzyme.

Transesterification reactions mediated by lipase LipC6G9 showed high enantiomeric ratio (E > 200), and enantiomeric excess of products (> 99\%; entries 1 and 2). The presence of nitro group led to increasing in the reaction time and lowering in conversion for $\mathbf{1 b}$ over 1a. Transesterification reactions of $\mathbf{1 a}$ and $\mathbf{1 b}$ mediated by LipC12 showed different selectivities. The enantiomeric ratio in resolution of 1 a was lower $(E=2$; entry 5$)$ than resolution reaction of $\mathbf{1 b}(E>200$; entry 6). Moreover, low conversion rates were achieved although longer reaction time for both compounds were required. On the other hand, hydrolysis reactions mediated by LipC6G9 beyond high enantiomeric excessess of products for the reactions of compounds 1c and 1d (entry 3 and 4), reduced reaction time and high conversion rate relative to transesterification reactions mediated by LipC12 and hydrolysis reactions mediated by LipC6G9 were observed.

\section{CONCLUSION}

Two lipases from metagenomic library were successfully evaluated, by the first, as biocatalyst in enzymatic kinetic resolution of racemic secondary alcohols and ester. In general, the products from kinetic resolutions reactions were obtained in high enantiomeric excesses inspite of requiring a long reaction time, which it is believed can be reduced through the optimization of the reaction parameters.

\section{ACKNOWLEDGEMENTS}

The authors thanks to CAPES, CNPq, Fundação Araucária and UFPR.

\section{REFERENCES}

${ }^{1}$ Handelsman, J.; Rondon, S. F.; Brady, J. and Clardy, R. M. Chem. Biol. 1998, 5, 245. ${ }^{2}$ Glogauer, A.; Martini, V. P.; Faoro, H.; Couto, G. H.; MüllerSantos, M.; Monteiro, R. A.; Mitchell, D. A.; Souza, E. M.; Pedrosa, F. O. and Krieger, N. Microb. Cell Fact. 2011, 108, 3335. ${ }^{3}$ Chen, C. Fujimoto, Y. Girdaukas, G. and Sih, J. J. Am. Chem. Soc.. 1982, 104, 7294. 